\title{
An L-Band, Circularly Polarized, Dual-Feed, Cavity-Backed Annular Slot Antenna with Wide-Angle Coverage
}

\author{
Larsen, Niels Vesterdal; Breinbjerg, Olav
}

Published in:

IEEE AP-S International Symposium

Link to article, DOI:

10.1109/APS.2006.1710850

Publication date:

2006

Document Version

Publisher's PDF, also known as Version of record

Link back to DTU Orbit

Citation (APA):

Larsen, N. V., \& Breinbjerg, O. (2006). An L-Band, Circularly Polarized, Dual-Feed, Cavity-Backed Annular Slot Antenna with Wide-Angle Coverage. In IEEE AP-S International Symposium (Vol. 2, pp. 1549-1552). IEEE. https://doi.org/10.1109/APS.2006.1710850

\section{General rights}

Copyright and moral rights for the publications made accessible in the public portal are retained by the authors and/or other copyright owners and it is a condition of accessing publications that users recognise and abide by the legal requirements associated with these rights.

- Users may download and print one copy of any publication from the public portal for the purpose of private study or research.

- You may not further distribute the material or use it for any profit-making activity or commercial gain

- You may freely distribute the URL identifying the publication in the public portal 


\title{
An L-band, Circularly Polarized, Dual-Feed, Cavity-Backed Annular Slot Antenna with Wide-Angle Coverage
}

\author{
Niels Vesterdal Larsen*1 and Olav Breinbjerg ${ }^{2}$ \\ ${ }^{1}$ nvl@oersted.dtu.dk, ${ }^{2} \mathrm{ob} @$ oersted.dtu.dk, \\ Ørsted $\bullet$ DTU, Technical University of Denmark, Ørsteds Plads \\ build. 348, DK-2800 Kgs. Lyngby, Denmark.
}

\begin{abstract}
An L-band, circularly polarized, dual-feed, cavity-backed annular slot antenna has been investigated. The investigations comprise parametric studies of design parameters and measurements with different ground planes. The antenna has an impedance bandwidth of $6 \%$ around $1.59 \mathrm{GHz}$ and a maximum directivity of about $7 \mathrm{dBi}$.
\end{abstract}

\section{Introduction}

This paper presents results from an investigation of a circularly polarized cavitybacked annular slot (CBAS) antenna. The antenna operates in the L-band around a center frequency of $1.6 \mathrm{GHz}$ and yield wide-angle coverage. It is possible to obtain circular polarization with only a single feed by employing various perturbations to the slot [1] or by shorting the slot [2], however, such solutions are usually associated with low axial ratio bandwidths and instead two feeds in phase quadrature are used. Similar antennas, though of different implementation, were previously reported in $[3,4]$. Initial design investigations comprise extensive numerical computer simulations using Ansoft's HFSS ver. 9.2. Subsequently, an antenna prototype has been constructed and measured at the DTU-ESA Spherical Near-Field Antenna Test Facility. Three different ground planes were used to investigate the influence of these

on the wide-angle performance of the antenna. A comprehensive documentation of the work on this antenna can be found in [5].

\section{Antenna Design and Impedance Characteristics}

The CBAS antenna is shown in figure 1. It consists of an annular slot, with mean radius $\rho_{s}$ and width $w_{s}$, which is etched in the single copper layer of a copper-clad Rogers RO-4003 substrate with the relative permittivity $\epsilon_{r}$ and thickness $t$. The annular slot is backed by a circular metallic cavity with interior radius $\rho_{c}$ and depth $h_{c}$ and mounted on a small circular ground plane. The annular slot is excited by two $50 \Omega$ coaxial cables, denoted feed 1 and feed 2 , respectively. Feed 2 is phased with a $90^{\circ}$ lag with respect to feed 1 resulting in right-hand circular polarization in the boresight direction. The harmonic time dependence $e^{j \omega t}$, with $t$ and $\omega$ being the time and angular frequency, respectively, is assumed and suppressed.

The values of the above design parameters were chosen on basis of extensive numerical simulations and are summarized in figure 1. The simulations have led to the following observations on the qualitative behavior of the resonance frequency $f_{\text {res }}$ and impedance bandwidth $B W$. 


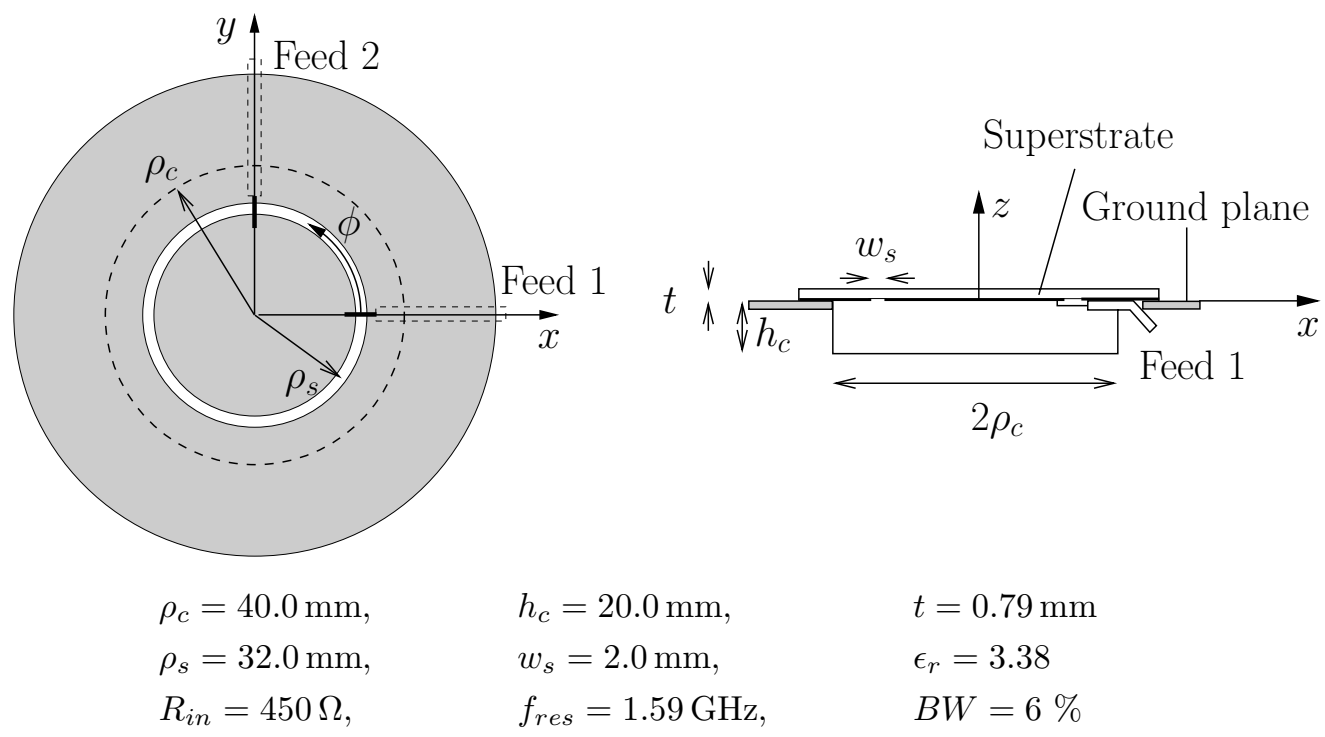

Figure 1: Geometry of the CBAS antenna and the chosen design parameters. For simplicity the dielectric superstrate is not shown on the top view.

- $f_{\text {res }}$ decreases for increasing values of the cavity dimensions $\rho_{c}$ and $h_{c}$ as well as slot parameters $\rho_{s}, \epsilon_{r}$, and $t$. It increases for increasing values of $w_{s}$.

- $B W$ increases for increasing values of $\rho_{c}, h_{c}$, and $w_{s}$ but has been found to be independent on $\rho_{s}$. It decreases for increasing values of $\epsilon_{r}$ and $t$.

The input impedances $Z_{i n, i}=R_{i n, i}+j X_{i n, i}$ and input reflection coefficients $\Gamma_{i n, i}$ at the two ports, $i=1,2$, can be determined from the antenna scattering matrix $\overline{\overline{\mathbf{S}}}$,

$$
\begin{aligned}
& Z_{i n, i}=Z_{0} \frac{\left(1+S_{i i}\right)\left(1-S_{j j}\right)+S_{i j} S_{j i}+2 S_{i j} \frac{V_{j}^{+}\left(1-S_{j j}\right)-V_{i}^{+} S_{j i}}{V_{i}^{+}\left(1-S_{i i}\right)-V_{j}^{+} S_{i j}}}{\left(1-S_{i i}\right)\left(1-S_{j j}\right)-S_{i j} S_{j i}}, \\
& \Gamma_{i n, i}=\frac{Z_{i n, i}-Z_{0}}{Z_{i n, i}+Z_{0}}, \quad j=3-i, i=1,2,
\end{aligned}
$$

where $V_{i}^{+}$is the incident voltage wave at the $i$ 'th feed port (defined at the intersection of the slot and coaxial cable). Equation (1) can be slightly reduced since $S_{12}=S_{21}$, and even further if perfect phase quadrature between the incident voltage waves is assumed, i.e., $V_{2}^{+}=-j V_{1}^{+}$, but, with (1) a non-ideal feed network can be taken into account.

In the left part of figure 2 the input impedances of the two ports are plotted assuming $V_{2}^{+}=-j V_{1}^{+}$for both simulated and measured scattering parameters. At the resonance frequency (defined at $X_{i n}=0$ ) they are approximately $450 \Omega$ for the simulation result, whereas they are slightly larger for the measurements. By assuming a $50 \Omega$ to $400 \Omega$ matching network the corresponding reflection coefficients have been calculated and are shown in the right part of figure 2 . The resonance frequency is approximately $1.59 \mathrm{GHz}$ with a bandwidth of $6 \%$ with respect to $\Gamma_{i n}<-10 \mathrm{~dB}$. The results from the simulation and measurement are generally in good agreement although slight deviations are seen for port 2 . 

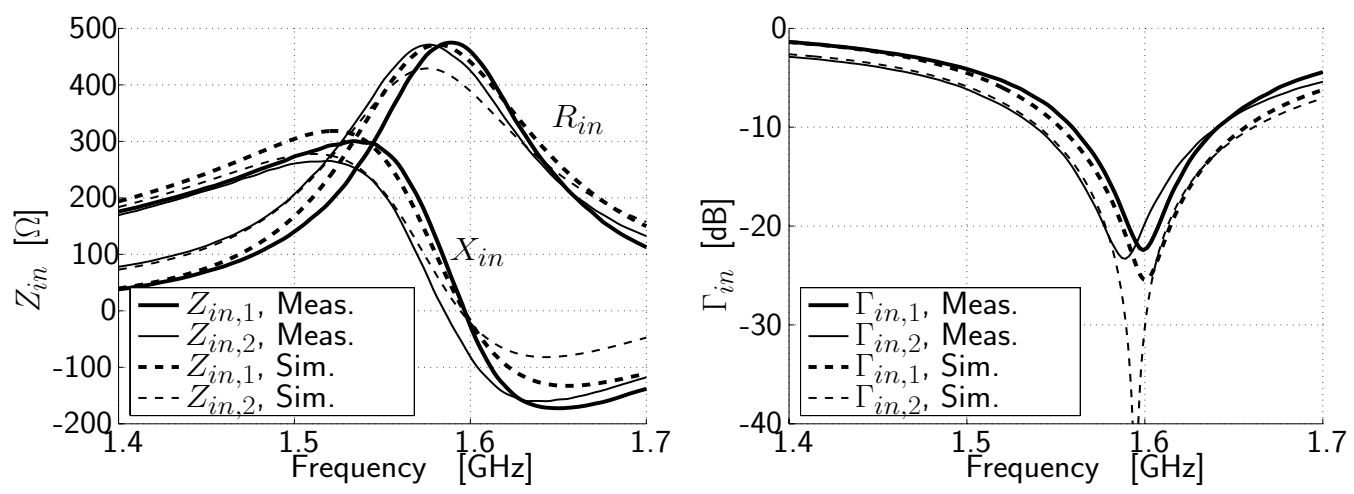

Figure 2: Input impedances $Z_{i n}=R_{i n}+j X_{\text {in }}$ and reflection coefficients $\Gamma_{i n}$ of the two input ports, assumed matched to $400 \Omega$.

\section{Radiation Characteristics for Different Ground Planes}

The antenna, fed using a quadrature hybrid, has been measured with three different ground planes attached behind the small circular one shown in figure 1. The changeable ground planes are denoted GP 1-3 and comprise a square one with side lengths of $250 \mathrm{~mm}$ and two circular ones with diameters of $360 \mathrm{~mm}$ and $1500 \mathrm{~mm}$, respectively. For the two small ground planes (GP 1-2) the simulations were carried out with HFSS, however, the large problem size for GP 3 rendered this approach impossible with the available computer resources. Instead a Method of Auxiliary Sources (MAS) [6] code was developed with the annular slot represented by a magnetic ring current. In figure 3 the radiation patterns are shown for GP 1 and GP 3 for $\phi=0^{\circ}$ together with the maximum directivity and boresight axial ratio as functions of frequency. In general the agreement between the measurements and simulations is good for both the co- and cross-polar components, both for HFSS and MAS simulations. As expected the amount of ripples present in the radiation patterns increases with the ground plane size, however, the maximum directivity and half power beam generally attain values around $7 \mathrm{dBi}$ and $100^{\circ}$, respectively. The fact that the axial ratio is nowhere lower than $1 \mathrm{~dB}$ implies that coupling between the feeds deteriorates the phase quadrature of the feed currents.

\section{Conclusion}

An L-band, circularly polarized, dual-feed, cavity-backed annular slot antenna has been developed. The antenna was equipped with three different ground planes and simulated using HFSS and a MAS code. Corresponding measurements have been conducted at the DTU-ESA Spherical Near-Field Antenna Test Facility and good agreement resulted. The antenna has an impedance bandwidth of $6 \%$ around a resonance frequency of $1.59 \mathrm{GHz}$ and an input impedance of approximately $450 \Omega$. The maximum co-polar directivity is about $7 \mathrm{dBi}$ and the half power beam width around $100^{\circ}$. Both, however, vary slightly for different ground planes. 

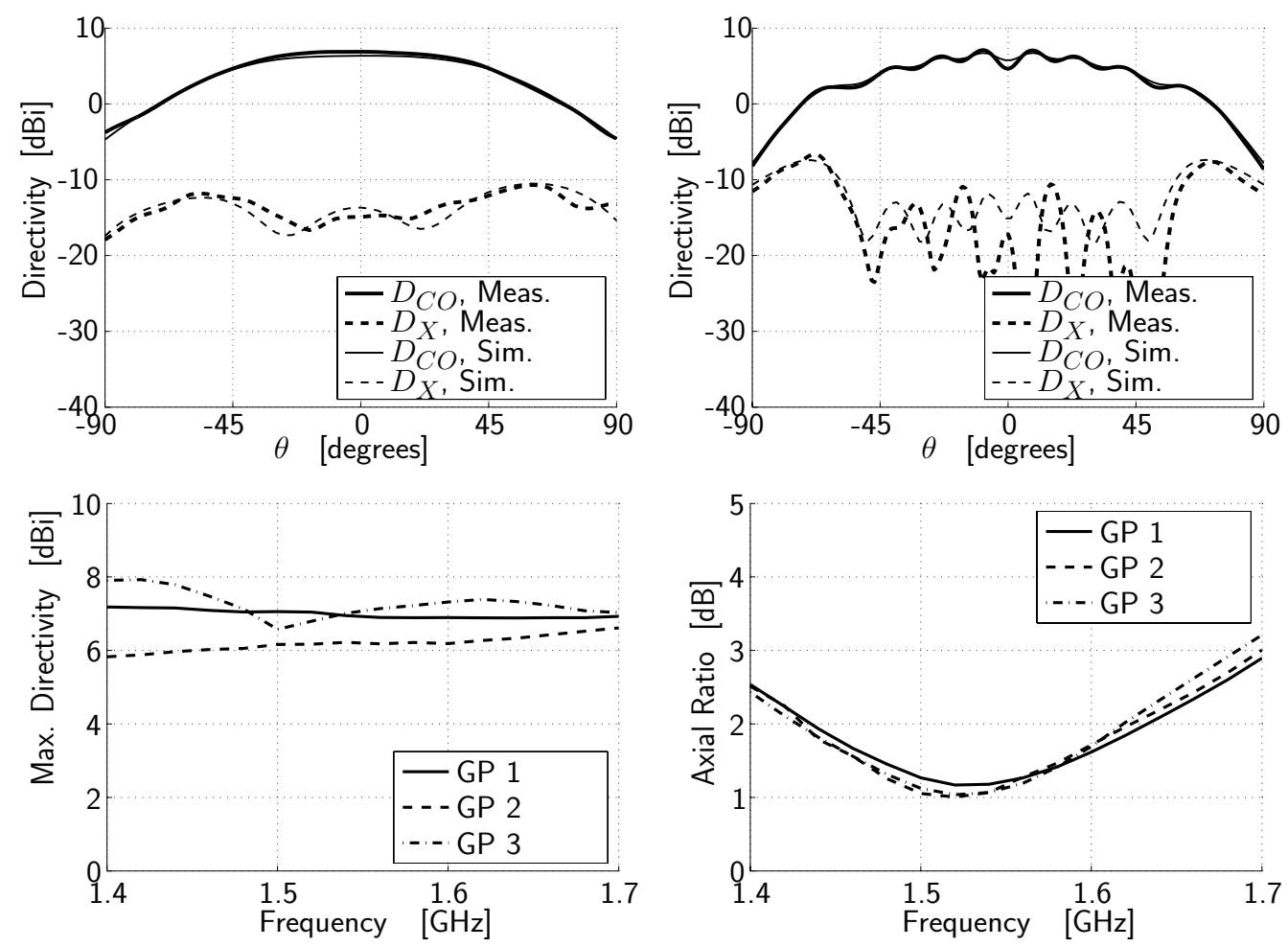

Figure 3: Top: directivity of the CBAS antenna for $\phi=0^{\circ}$ as function of $\theta$ for GP 1 (left) and GP 3 (right) at $1.58 \mathrm{GHz}$. Bottom: maximum directivity (left) and axial ratio at boresight (right) as function of frequency for GP 1-3.

\section{References}

[1] M.K. Fries \& R. Vahldieck, "Uniplanar Circularly Polarized Slot-Ring Antenna Architectures", Radio Science, Vol. 38, No. 2, pp. 5.1-5.10, 2003.

[2] H. Morishita et al., "Analysis of a Cavity-Backed Annular Slot Antenna with One Point Shorted", IEEE Trans. Antennas Propagat., Vol. 39, No. 10, pp. 1472-1478, 1991.

[3] X.M. Qing \& Y.W.M. Chia, "Circularly Polarised Circular Ring Slot Antenna Fed by Stripline Hybrid Coupler", Electron. Lett., Vol. 35, No. 25, pp. 2154-2155, 1999.

[4] N.C. Karmakar, "Investigations Into a Cavity-Backed Circular-Patch Antenna", IEEE Trans. Antennas Propagat., Vol. 50, No. 12, pp. 1706-1715, 2002.

[5] N.V. Larsen \& O. Breinbjerg, "An L-band, Circularly Polarised, Dual-Feed, Cavity-Backed Annular Slot Antenna for Phased Array Applications", in submission, October, 2005.

[6] H.T. Anastassiu et al., "Electromagnetic Scattering Analysis of Coated Conductors With Edges Using the Method of Auxiliary Sources (MAS) in Conjunction With the Standard Impedance Boundary Condition (SIBC)", IEEE Trans. Antennas Propagat., Vol. 50, No. 1, January 2002, pp. 59-66. 